was used to model the differences in the comorbidity indices between race groups.

Results: 453 EMRAC subjects were analyzed; 342 (81.4\%) were female, average age was 58.9 ( \pm 15.1 ) years, average duration $13.3( \pm 11.1)$ years and average follow-up length $2.1( \pm 1.4)$ years. Individual comorbid frequencies as well as comorbid indices are summarized in Table 1. Spearman correlation between overall RDCl and COUNT was $0.90(95 \% \mathrm{Cl}[0.88,0.91], \mathrm{P}<0.001)$. Hispanics, however, had significantly lower comorbidity indices scores than other race groups ( $R D C I$ Hispanic vs White $P=0.003$, Hispanic vs Black $P=0.004$, Hispanic vs Other $\mathrm{P}=0.038$; COUNT Hispanic vs White $\mathrm{P}=0.012$, Hispanic vs Black $\mathrm{P}=0.004$, Hispanic vs Other $\mathrm{P}=0.151)$.

Table 1. Clinical Characteristics of EMRAC study cohort

\begin{tabular}{lccccc}
\hline & White & Black & Hispanic & Other & Total \\
\hline $\mathrm{N}$ & 102 & 195 & 85 & 71 & 453 \\
Hypertension [N (\%)] & $36(35.3 \%)$ & $79(40.5 \%)$ & $24(28.2 \%)$ & $31(43.7 \%)$ & $170(37.5 \%)$ \\
Coronary Artery Disease [N (\%)] & $12(11.8 \%)$ & $14(7.2 \%)$ & $3(5.9 \%)$ & $2(2.8 \%)$ & $31(6.8 \%)$ \\
Other Heart Disease [N (\%)] & $11(10.8 \%)$ & $6(3.1 \%)$ & $2(2.4 \%)$ & $2(2.8 \%)$ & $21(4.6 \%)$ \\
Fracture [N (\%)] & $11(10.8 \%)$ & $8(4.1 \%)$ & $2(2.4 \%)$ & $2(2.8 \%)$ & $23(5.1 \%)$ \\
Psychiatric Disease [N (\%)] & $5(4.9 \%)$ & $10(5.1 \%)$ & $1(1.2 \%)$ & $0(0.0 \%)$ & $16(3.5 \%)$ \\
Diabetes [N (\%)] & $11(10.8 \%)$ & $33(16.9 \%)$ & $9(10.6 \%)$ & $8(11.3 \%)$ & $61(13.5 \%)$ \\
Cancer [N (\%)] & $9(8.8 \%)$ & $8(4.1 \%)$ & $5(5.9 \%)$ & $3(4.2 \%)$ & $25(5.5 \%)$ \\
Stomach [N (\%)] & $8(7.8 \%)$ & $9(4.6 \%)$ & $8(9.4 \%)$ & $7(9.9 \%)$ & $32(7.1 \%)$ \\
Stroke [N (\%)] & $4(3.9 \%)$ & $6(3.1 \%)$ & $2(2.4 \%)$ & $2(2.8 \%)$ & $14(3.1 \%)$ \\
Hyperlipidemia [N (\%)] & $19(18.6 \%)$ & $29(14.9 \%)$ & $9(10.6 \%)$ & $12(16.9 \%)$ & $69(15.2 \%)$ \\
Chronic Bronchitis [N (\%)] & $10(9.8 \%)$ & $17(8.7 \%)$ & $5(5.9 \%)$ & $5(7.0 \%)$ & $37(8.2 \%)$ \\
Pulmonary Fibrosis [N (\%)] & $2(2.0 \%)$ & $5(2.6 \%)$ & $4(4.7 \%)$ & $0(0.0 \%)$ & $11(2.4 \%)$ \\
Kidney Disease [N (\%)] & $3(2.9 \%)$ & $5(2.6 \%)$ & $0(0.0 \%)$ & $2(2.8 \%)$ & $10(2.2 \%)$ \\
RAPID3 & $13.1(6.8)$ & $12.5(7.4)$ & $14.8(6.9)$ & $13.7(7.2)$ & $13.3(7.1)$ \\
Enrollment & & & & & \\
RDCl & $1.8(2.1)$ & $1.7(2.0)$ & $1.2(1.7)$ & $1.6(1.8)$ & $1.6(1.9)$ \\
COUNT & $1.0(1.3)$ & $1.0(1.3)$ & $0.7(0.9)$ & $0.9(1.1)$ & $0.9(1.2)$ \\
\hline Mean (SD) reported unt
\end{tabular}

Mean (SD) reported unless otherwise noted.

Conclusions: In an ethnic RA subset, the RCDI and COUNT correlated well across ethnic groups. The comorbidity indices were not associated with RA disease activity at enrollment as assessed by the RAPID3. Hispanics had lower RCDI and COUNT scores compared to other race groups but also presented at a younger age which could account for this difference. More studies are needed to determine the predictive value of these indices in determining poor outcomes and mortality in this ethnic subset.

References:

[1] England, BR et al. Arthritis Care Res. 2015 Jun; 67(6): 885-872.

Disclosure of Interest: S. Dowell Grant/research support from: Bristol Myers Squibb, Pfizer, Genentech, Speakers bureau: Horizon Pharma, G. Kerr Grant/research support from: Bristol Myers Squibb, Pfizer, Genentech, C. Swearingen Grant/research support from: Bristol Myers Squibb, Pfizer, Genentech, M. Quinones Grant/research support from: Bristol Myers Squibb, Pfizer, Genentech, J. Berrian Grant/research support from: Bristol Myers Squibb, Pfizer, Genentech, S. Hochberg Grant/research support from: Bristol Myers Squibb, Pfizer, Genentech DOI: 10.1136/annrheumdis-2017-eular.5842

\section{SAT0130 EVALUATION OF THE FACTORS RELATED WITH RISK OF FALLING AND FEAR OF FALLING IN PATIENTS WITH RHEUMATOID ARTHRITIS}

S. Unsal Delialioglu ${ }^{1}$, G. Kilinc Kamaci ${ }^{1}$, S. Ozel ${ }^{1}$, F. Yurdakul ${ }^{2}$, H. Bodur ${ }^{2}$ ${ }^{1}$ Ankara Physical Therapy and Rehabilitation Training and Research Hospital; ${ }^{2}$ Ankara Numune Training and Research Hospital, Ankara, Turkey

Background: People with rheumatoid arthritis (RA) have an increased risk of falls $(1,2)$. The identification of predictive and potentially modifiable risk factors is essential for the development of effective falls prevention strategies (3).

Objectives: The aim of the study is to determine the relationship between falling risk and falling fear with balance, lower extremity muscle strength, functional status, disease activity and pain in patients with Rheumatoid Arthritis (RA)

Methods: A total of 124 patients (92 females, 32 males) who were diagnosed with RA according to the American College of Rheumatology (ACR) diagnostic criteria were included in the study. The fear of falling was assessed by the Fall Efficacy Scale (FES-I) and the shortened form (Short FES-I). Disease activity was assessed using the Disease Activity Score-28 (DAS28), the functional status was assessed with Health Assessment Questionnaire (HAQ). While lower extremity muscule strenght was determined using Chair Stand Test, Four Balance Test was used to determine the balance. The pain intensity was determined using $10 \mathrm{~cm}$ Visual Analogue Scale-Pain (VAS-pain).

Results: The mean age of the patients is $54.75 \pm 10.96$ years, the mean duration of illness is $14.10 \pm 10.99$ years. A statistically significant relationship was found between FES-I, Short FES-I scores and HAQ (respectively $r: 0,776, p: 0,000$; $r: 0,783, p: 0,000)$, VAS rest $(r: 0.397, p: 0,000 ; r: 0,405, p: 0,000)$, VAS motion $(r: 0.542, p: 0,000 ; r: 0,519, p: 0,000)$, DAS28 values $(r: 0.216, r: 0.181 ; r: 0,260$, p:0,004). There was a significant negative correlation between FES-I, Short FES-I scores and Chair Stand Test (respectively r:-0.644, p:0,000; r:-0.652, p:0,00), Four Balance Test ( $r:-0.597, \mathrm{p}: 0,000 ; \mathrm{r}:-0.611, \mathrm{p}: 0,00)$. There was a statistically significant correlation between the number of falls in the last year and age, duration of illness, $H A Q$, DAS28, VAS scores $(p<0,05)$
Conclusions: The risk of falling and fear of falling is associated with balance, lower extremity muscle strength, disease activity, functional status, and pain in patients with RA. Therefore; the risk of falling and fear of falling should be determined and necessary measures must be taken in patients with RA.

References:

[1] Böhler C, Radner H, Ernst M, Binder A, Stamm T, Aletaha D, Smolen JS, Köller M. Rheumatoid arthritis and falls: the influence of disease activity. Rheumatology (Oxford). 2012 Nov;51(11):2051-7.

[2] Armstrong C, Swarbrick CM, Pye SR, O'Neill TW. Occurrence and risk factors for falls in rheumatoid arthritis Ann Rheum Dis. 2005 Nov;64(11):1602-4.

[3] Stanmore EK, Oldham J, Skelton DA, O'Neill T, Pilling M, Campbell AJ, Todd C. Risk factors for falls in adults with rheumatoid arthritis: a prospective study. Arthritis Care Res (Hoboken). 2013 Aug;65(8):1251-8.

Disclosure of Interest: None declared

DOI: 10.1136/annrheumdis-2017-eular.2022

\section{SAT0131 MEDIAN NERVE THICKNESS RELATED TO RENAL IMPAIRMENT IN RHEUMATOID ARTHRITIS}

S. Hannawi ${ }^{1}$, I. AISalmi ${ }^{2} .{ }^{1}$ Rheumatology, Ministry of Health and Prevention of UAE, Dubai, United Arab Emirates; ${ }^{2}$ Nephrology, Royal Hospital, Muscat, Oman

Background: Autoimmune processes, contribute to the burden of kidney disease The reported kidney disease prevalence in patients with rheumatoid arthritis (RA) ranges from $5 \%>50 \%$ based on studies of different designs. Historically, patients with RA-associated renal amyloidosis had higher mortality rates relative to the general population. The occurrence of haematuria, proteinuria, or CKD has been reported to be associated with a 3 - to 4 -fold increased risk of death. Subclinical decreased kidney function has been identified as an independent risk factor for cardiovascular $(\mathrm{CV})$ events with increase mortality in patients with RA. On the other hand, both rheumatoid arthritis and renal impairment have been reported to be associated with increase prevalence of carpal tunnel syndrome.

Objectives: To establish the median nerve thickness (measured by ultrasound) in RA and its relation to renal function.

Methods: 120 RA patients were recruited through a specialized rheumatology clinic. The US measurements were performed by the same person. Patients were sitting with their forearm resting in a supinated position on a small table. The US probe (an 8-16 MHz linear array transducer) was held as lightly as possible to avoid disturbing the anatomy of the nerve. The median nerve was examined at the entrance of the carpal tunnel, between the pisiform bone and the tubercle of the scaphoid bone, where the distal volar crease is an external pisiform landmark. A continuous trace was made just within the hyperechogenic boundary of the nerve. The cross-sectional area of the median nerve was calculated directly by the software of the US equipment. Each median nerve was measured three times, and the mean value was used for further analyses. Modification of Diet in Renal Disease (MDRD) equation used to estimate the Glomerualr Filatration Rate (GFR). The average of the right and the left areas of the median nerve were used when exploring bivariate correlations to the renal variables (Pearson's correlation coefficients). All statistics were performed using STATA programe.

Results: the average median nerve thickness was $9.79 \pm 2.6 \mathrm{~mm}^{2}$ (Range 1.5 -22.25). The average GFR was $122 \pm 20 \mathrm{ml} / \mathrm{min}$ (59.6-286). Thickness of the median nerve was positively associated with the age of the participants $(p=0.03$, $\mathrm{Cl}: 0.00,0.08)$, body mass index $(\mathrm{p}=0.04, \mathrm{Cl}: 0.00,0.21)$, uric acid level $(\mathrm{p}=0.033$, $\mathrm{Cl}: 0.00,0.01)$, and urine microalbumin $(\mathrm{p}=0.04, \mathrm{Cl} 0.00,0.01)$. GFR showed no significant relation the thickness of the median nerve.

Conclusions: RA patients without symptoms or clinical signs have a median nerve thickness that is positively correlated to the level of microalbumin and uric acid. Whether sosnographic examination of the median nerve would be helpful in predicting who is going to have a deteriorated renal function need to be explored in a larger study.

\section{References:}

[1] Boers, M., et al., Subclinical renal dysfunction in rheumatoid arthritis. Arthritis Rheum, 1990 33(1): p. 95-101.

[2] Daoussis, D., et al., Cardiovascular risk factors and not disease activity, severity or therapy associate with renal dysfunction in patients with rheumatoid arthritis. Ann Rheum Dis, 2010. 69(3): p. 517-21.

[3] Pathan, E. and V.R. Joshi, Rheumatoid arthritis and the kidney. J Assoc Physicians India, 2004 52: p. 488-94.

Disclosure of Interest: None declared

DOI: 10.1136/annrheumdis-2017-eular.1660

\section{SAT0132 THE RHEUMATOID ARTHRITIS FLARE QUESTIONNAIRE (RA-FQ): RESULTS OF RASCH ANALYSIS AND FEEDBACK ON REAL-WORLD APPLICATIONS FROM INTERNATIONAL RA PATIENTS AND CLINICIANS}

S.J. Bartlett ${ }^{1,2}$, S.P. Barbic ${ }^{3}$, V.P. Bykerk ${ }^{4}$, B. Fautrel ${ }^{5}$, F. Guillemin ${ }^{6}$, A. den Broeder $^{7}$, R. Alten ${ }^{8}$, R. Christensen ${ }^{9}$, E. Choy ${ }^{10}$, D. Furst ${ }^{11}$, S. Hewlett ${ }^{12}$, A. Leong ${ }^{13}$, L. March ${ }^{14}$, T. Woodworth ${ }^{11}$, B.I.O. Clifton ${ }^{2}$ on behalf of CATCH, STPR, \& DRESS Investigators. ${ }^{1}$ Mc Gill University, Montreal, Canada; ${ }^{2} J o h n s$ Hopkins, Baltimore, United States; ${ }^{3}$ University of British Columbia, Vancouver, Canada: ${ }^{4}$ HSS, New York. United States: ${ }^{5}$ Pierre \& Marie Curie Universite, Paris; 
${ }^{6}$ Universite de Lorraine, Nancy, France; ${ }^{7}$ Maartens Kliniek, Nijmegen, Netherlands; ${ }^{8}$ Schlosspark Klinik, Berlin, Germany; ${ }^{9}$ Parker Institute, Copenhagen, Denmark; ${ }^{10}$ Cardiff University, Cardiff, United Kingdom; ${ }^{11}$ UCLA, Los Angeles, United States; ${ }^{12}$ University of the West of England, Bristol, United Kingdom; ${ }^{13}$ Healthy Motivation, Santa Barbara, United States; ${ }^{14}$ University of Sydney, Sydney, Australia

Background: Disease flares in RA are common. The RA Flare Questionnaire (RA-FQ) can be used to identify and quantify flares in rheumatoid arthritis (RA). Objectives: To further explore the psychometric properties RA-FQ, we used Rasch analysis and reviewed results with RA patients research partners (PRPs) and clinicians to gain additional insight into the interpretability, meaningfulness, and utility of results.

Methods: People with RA in observational trials in Canada (CATCH; $n=896$ ) and France (STPR; $n=138$ ), and an RCT in the Netherlands ( $n=178$ ) completed the RA-FQ. RUMM2030 was used to evaluate unidimensionality, targeting of items to people, reliability, response options, redundancy, local dependence, and response bias by sex, across age categories, and by country/language. ROC curves were used to identify sensitivity and specificity across potential threshold values to identify flares in different contexts of use. We reviewed results with RA patients research partners (PRPs) to gain additional insight into the interpretability, meaningfulness, and utility of results. Ten PRPs first completed the questionnaire then reviewed individual and group findings to provide feedback. RA clinicians provided feedback on utility and relevance of proposed cut points to identify flares. Results: Rasch results supported the simple summation of items for a total score ranging from $0-50$. Each item had ordered thresholds and acceptable fit. Reliability, was high ( $\mathrm{PSI}=.91$ ). Items and people covered a continuum ranging from -3.2 to +3.4 logits, and items were well-targeted to respondents. Overall model fit was excellent $\left(x^{2}=31.6, d f=45 ; p=0.935\right)$. There was little evidence of differential item functioning by sex, age, or country/language. Items suggest flare symptoms and impacts increased together showing a consistent story of how individuals experience worsening RA disease activity. Among PRPs, scores ranged from 10 to 41 . There was unanimous agreement from the patients that the story depicted and individual results obtained were easily understood, meaningful, and very reflective of their current state. Many patients noted that beyond clinical trials, the RA-FQ could also enhance communication between doctors and patients at routine visits. Several noted potential applicability in monitoring day-to-day status and with self management. Thresholds for clinically important worsening to identify flare varied by setting, patient population, and context of use.

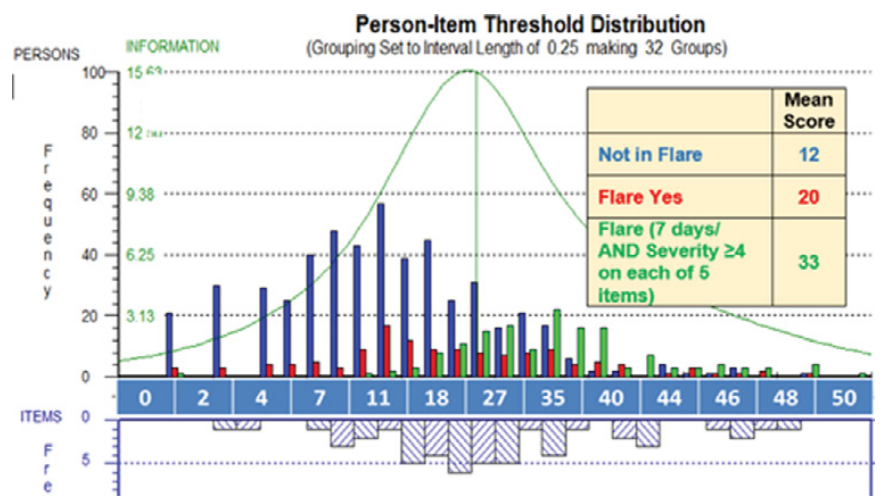

Conclusions: Taken together, results from classical and Rasch analyses support for the robust psychometric properties of the RA-FQ. The 5 -item measure is easy to complete and simple to score. Feedback from RA PRPs and clinicians increase confidence in the relevance, meaningfulness, and easy interpretation of RA-FQ results for clinicians, researchers, and patients.

Disclosure of Interest: None declared

DOI: 10.1136/annrheumdis-2017-eular.5593

\section{SAT0133 SUDOMOTOR DYSFUNCTION IN RHEUMATOID ARTHRITIS PATIENTS IN THE ABSENCE OF TRADITIONAL CARDIOVASCULAR RISK}

T. Syngle ${ }^{1}$, S. Kaur ${ }^{2}$, I. Verma ${ }^{3}$, A. Syngle ${ }^{4} .{ }^{1} \# 547$, Sector $16 D$, Chandigarh, India, Healing Touch Foundation, Chandigarh, India; ${ }^{2}$ Cardio-Rheuma \& Healing Touch City Clinic, Chandigarh; ${ }^{3}$ Maharishi Markandeshwar College of Pharmacy, M.M University, mullana; ${ }^{4}$ Cardio-Rheuma \& Healing Touch City Clinic and Fortis Multi Specialty Hospital, Chandigarh, India

Background: Rheumatoid arthritis (RA) is an autoimmune chronic inflammatory disease associated with cardiovascular autonomic neuropathy. Cardiovascular autonomic neuropathy is a significant risk predictor for sudden cardiac death in rheumatoid arthritis. ${ }^{1}$ Sudomotor dysfunction reflects small fibre neuropathy, cardiovascular autonomic neuropathy and peripheral sympathetic autonomic neuropathy. ${ }^{2}$ However, sudomotor dysfunction and its relationship with inflammatory measures remain unexplored in RA patients in the absence of traditional cardiovascular (CV) risk factors.

Objectives: The aim of present study was to assess the sudomotor function and its association with disease specific measures: ESR, CRP and DAS-28 in RA patients with no apparent conventional cardiovascular risk factor.

Methods: In this cross-sectional study, 60 RA patients fulfilling 2010 Rheumatoid Arthritis Classification Criteria ${ }^{3}$ and 40 age and sex-matched healthy controls were recruited. Sudomotor function was assessed using Sudoscan (Impeto Medical, Paris, France) through measurement of electrochemical skin conductance of hands and feet. ${ }^{2}$ Sudoscan investigates the sweat gland activity and used as a surrogate to study the damage of sympathetic sudomotor nerves in neuropathy. It is an indirect assessment tool of sudomotor function. Inflammatory measures such as ESR and CRP and DAS-28 (disease activity score in 28 joints) were determined.

Results: Rheumatoid arthritis patients had significantly impaired sudomotor function ( $56.90 \pm 12.95$ vs. $76.15 \pm 8.45 \mu \mathrm{s}, p<0.00$, Figure $1 \mathrm{~A}$ ), elevated ESR $(31.30 \pm 12.34$ vs. $16.72 \pm 4.46, p<0.001)$ and $\operatorname{CRP}(10.55 \pm 3.81$ vs. $3.81 \pm 1.03$, $\mathrm{p}=0.002$ ) as compared to healthy controls, respectively. The mean disease duration of RA patients was $9.15 \pm 5.76$ and they had high disease activity (mean DAS-28, 4.60 \pm 1.72$)$. Sudomotor function was found to be inversely correlated with ESR $(r=0.42, p=0.001$, Figure 1B), CRP $(r=0.60, p<0.001$, Figure 1C) and DAS-28 $(r=0.38, p=0.003$, Figure 1D).

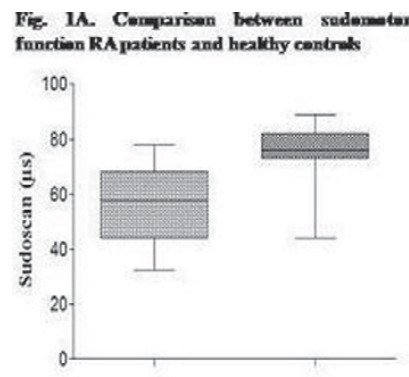

RA
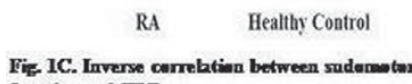

function and CRP

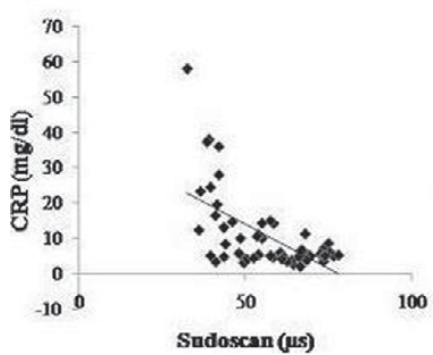

Conclusions: Cardiovascular autonomic neuropathy occurs in RA in the absence of traditional CV risk factors. Sudomotor dysfunction is significantly associated with increased level of ESR, CRP and disease activity suggesting that increased inflammation may cause sudomotor dysfunction.

References:

[1] Milovanovic B et al. Srp Arh Celok Lek 138:26-32.

[2] Mayaudon $\mathrm{H}$ et al. Diabetes Metab. 2010;36:450-54

[3] Aletaha D et al. Arthritis Rheum. 2010;62:2569-81.

Acknowledgements: None.

Disclosure of Interest: None declared

DOI: 10.1136/annrheumdis-2017-eular.4382

\section{SAT0134 DAILY MONITORING OF ARTERIAL STIFFNESS IN WOMEN WITH RHEUMATOID ARTHRITIS}

T.A. Romanova, N.M. Nikitina, A.P. Rebrov. Hospital Therapy Department, State Medical University of Saratov, Saratov, Russian Federation

Background: Patients with rheumatoid arthritis (RA) have an increased risk of cardiovascular (CV) disease. Monitoring of arterial stiffness could be used as an additional tool of cardiovascular risk assessment.

Objectives: of the study is to evaluate the main parameters daily monitoring of arterial stiffness (DMAS) in women with rheumatoid arthritis with or without arterial hypertension $(\mathrm{AH})$.

Methods: DMAS was measured in 63 women with RA (ACR 1987 and/or EULAR/ACR 2010 criteria). The first group involved 39 RA female patients with $\mathrm{AH}$ (mean age $-58.3 \pm 6.08$ years; median of RA duration - $8[4 ; 14]$ years, median of DAS 28- 5.08 [4.04; 5.85]), the second group included 24 women with RA without AH (mean age $55 \pm 7.15$ years; duration of RA is 10 [3; 17] years, mean DAS $28-5.25[4.6 ; 5.7])$

30 women with $A H$ without RA and other joint diseases and 22 healthy females were involved as a controls. Persons with and without RA were comparable 